\title{
Commentary: Evidence-Based Principles for Pronunciation Teaching \& ESL Immersion and Pronunciation Development
}

\author{
Sinem Sonsaat Hegelheimer* \\ Department of English, lowa State University, Ames, IA, United States
}

Keywords: pronunciation teaching, functional load, immersion context, suprasegmentals, Spanish, English

\section{A Commentary on}

Evidence-Based Principles for Pronunciation Teaching \& ESL Immersion and Pronunciation Development

by Colantoni L., Escudero P., Marrero-Aguiar V., and Steele J. (2021). Front. Commun. 6:639889. doi: 10.3389/fcomm.2021.639889

\section{OPEN ACCESS \\ Edited by:}

Antonio Benítez-Burraco,

Sevilla University, Spain

Reviewed by:

Andrew Sewell,

Lingnan University, Hong Kong SAR,

China

*Correspondence:

Sinem Sonsaat Hegelheimer sonsaat@iastate.edu

Specialty section:

This article was submitted to

Language Sciences,

a section of the journal

Frontiers in Communication

Received: 01 October 2021 Accepted: 25 October 2021 Published: 22 November 2021

Citation:

Sonsaat Hegelheimer S (2021)

Commentary: Evidence-Based

Principles for Pronunciation Teaching \&

ESL Immersion and

Pronunciation Development.

Front. Commun. 6:788177.

doi: 10.3389/fcomm.2021.788177

\section{"EVIDENCE-BASED DESIGN PRINCIPLES FOR SPANISH PRONUNCIATION TEACHING" (COLANTONI, ESCUDERO, MARRERO-AGUIAR, AND STEELE)}

There is a plethora of research exploring how English pronunciation should be taught or what features should be prioritized in teaching to help improve learners' intelligibility. However, there is not much published on the same issue in other languages. Because each language has its own phonetic inventory, phonological idiosyncrasies and variations, research on issues related to teaching priorities in English pronunciation may be helpful but not fully applicable to other languages. This conceptual analysis on five research-informed design principles discussing the priorities and considerations for Spanish pronunciation teaching is important and informative for researchers, practitioners, and materials developers.

Of the five principles, "a focus on features with high functional load" is especially valuable. In this section, the authors suggest a frequency-based method to reach conclusions about which sounds are more important to address at different levels of L2 Spanish learning. For teachers who do not feel very confident about what sounds to prioritize in pronunciation instruction, the authors provide a list of the most frequent sounds in Spanish and guide readers about the importance of minimal pairs in determining the importance of sound contrasts. In a further study, the authors could potentially create a rank ordering of Spanish sound pairs (for the variety of their choice) that is likely to cause intelligibility problems by following a method such as the one in Brown (1988). The authors criticize the functional load principle for not addressing suprasegmental features and suggest ways of incorporating lexical stress and sentence-type intonation into the functional load principle. Functional load, as we usually understand it, is built primarily on numbers of minimal pairs for a given contrast. But this feature is not easily applicable to suprasegmentals. Perhaps we need a different measure altogether. Such a measure does exist in the form of the information-theoretic approach to functional load, outlined by Hockett (1967) and elaborated by Surendran and Niyogi (2003); see also Sewell, 2021). The work of Surendran and Niyogi (2003) focused on the relative contributions of vowels, consonants, and lexical stress etc. for English, Dutch, German, and 
Mandarin, but there is still need for research focusing on Spanish. This might be a potential future exploration both for the authors of this paper and other researchers.

Another helpful section of this paper is the one on 'targeting features and segments shared by the majority of the varieties of the target language since it brings attention to the commonly shared features in most Spanish varieties. The authors propose that commonly shared sounds in most Spanish varieties should be prioritized in pronunciation instruction to support mutual intelligibility and inform about the most appropriate developmental stage (i.e., proficiency level) to address particular dialectal features. In this section, the authors increase the visibility of research done in Spanish varieties by not only reviewing the studies published in English but also the ones in Spanish.

One of the contributions of this paper is to highlight the role of prosody in Spanish, that is, marking inflectional features through lexical stress and sentence structure through intonation (i.e., declaratives versus questions). Having called attention to the distinct role of prosody in Spanish, the paper might be strengthened by reviewing the studies addressing prosody in Spanish. Most studies cited in the current paper focus on prosody in English.

In conclusion, the conceptual analysis in this paper provides a foundation for the further development of Spanish pronunciation teaching. Particularly important is its consideration of the importance of perceptual training, the role of prosodic components in Spanish, the use of contextualized activities, the importance of extending research on functional load to Spanish, and the benefits of teaching pronunciation features that are shared across Spanish varieties.

\section{"THE EFFECTS OF ESL IMMERSION AND PROFICIENCY ON LEARNERS' PRONUNCIATION DEVELOPMENT" (KOSTROMITINA AND KANG)}

The development of segmental and suprasegmental pronunciation features in L2 English is a commonly studied topic in pronunciation instruction studies in laboratory or classroom settings (for example, see Lee et al., 2015). In longitudinal studies, however, it is mostly global measures of speech such as comprehensibility, accentedness, and fluency that are explored. It is less common to see studies in which the development of multiple segmental and suprasegmental features is reported over an extended period of time. This exploratory study differs by investigating ESL speakers' development of segmentals and suprasegmentals (i.e., fluency, prominence, and intonation) in an immersion context without any classroom instruction.

The study has a number of features that enable it to capture ESL speakers' pronunciation development in a more holistic way. First, it explores pronunciation issues using elicited free speech data (extended samples of monologic speech), which is challenging while looking at segmentals since speakers may not produce sufficient tokens for some sounds. Second, rather than focusing on a selected set of sounds, the authors map out the developmental trajectory of all segmentals by employing a functional load-based analysis. Third, fluency, prominence, and intonation are analyzed through acoustic measures rather than listener-based judgements to give a more fine-detailed picture of learners' development. Lastly, this study compares the development of beginner, intermediate and advanced speakers to investigate the relationship between proficiency level and developmental patterns, providing information about whether there is an optimal time to be immersed into the second language environment.

The study reports no significant improvement for segmental features across proficiency levels. In fact, the proficiency levels of the speakers and the immersion experience could explain only about $2 \%$ of the change in L2 speakers' speech and the authors report that most of the variance was explained by individual differences among the participants. For suprasegmentals, the study reports significant effects of immersion experience with medium to large effect sizes only for some features (fluency and prominence) but not across all proficiency levels. As for intonation, there was no significant effect of immersion but only of proficiency level. Indeed, for all features in the study, individual differences were influential and the study as a whole points to the importance of both external factors (such as age of onset) and internal factors (such as motivation) in explaining the development of L2 pronunciation. The authors also reported substantial influence of random factors (i.e., participants and their L1 background) based on their Linear Mixed Effects Models analyses. This study is important in terms of showing the importance of individual differences since "participants" was the random factor accounting for so much difference in speakers' performances. The study is also important in emphasizing the need for explicit training to support the improvement of productive speech and pronunciation skills of L2 speakers. Lastly, the results of this exploratory study bring up the question of the optimal proficiency level that is required for L2 speakers to benefit from an immersion experience. This study reinforces the findings of previous research showing the importance of both segmentals and suprasegmentals (Pickering, 2001; Hahn, 2004; Field, 2005; Kang, 2010; Kang et al. 2010; Kang and Moran, 2014) for L2 pronunciation performance and how they may follow different developmental trajectories for speakers who started their immersion experience at different levels (Collentine, 2009; Davidson, 2010; Kang and Ghanem, 2016). It also indicates that some pronunciation features may be quite challenging to acquire, at least in a short time frame.

The way this study lies at the crossroads of multiple research topics (i.e., functional load, segmentals and suprasegmentals, immersion contexts) reflects the ongoing research agenda of Okim Kang and her collaborators, whose work on functional load and the role of suprasegmentals in L2 pronunciation has pushed the field forward in connecting acoustic measurements and listener-based ratings (Kang et al., 2010; Kang, 2012; Kang and Moran, 2014; Kang et al., 2020).

\section{AUTHOR CONTRIBUTIONS}

The author confirms being the sole contributor of this work and has approved it for publication. 


\section{REFERENCES}

Brown, A. (1988). Functional Load and the teaching of pronunciation. TESOL Q. 22 (4), 593-606. doi:10.2307/3587258

Collentine, J. G. (2009). "Study abroad research: Findings, implications, and future directions," in The handbook of language teaching. Editors M. H. Long and C. J. Catherine (UK: Wiley), 218-233.

Davidson, D. E. (2010). Study abroad: When, how Long, and with what results? New data from the Russian front. Foreign Lang. Ann. 43 (1), 6-26.

Field, J. (2005). Intelligibility and the Listener: The role of Lexical stress. TESOL Q. 39 (3), 399-423.

Hahn, L. D. (2004). Primary stress and intelligibility: Research to motivate the teaching of suprasegmentals. TESOL Q. 38 (2), 201-223. doi:10.2307/3588378

Hockett, C. (1967). The quantification of functional Load. Word 23, 320-339. doi:10.1080/00437956.1967.11435484

Kang, O., and Ghanem, R. (2016). Learners' self-perception of target Language study in overseas immersion. J. Lang. Teach. Res. 7 (5), 819-828.

Kang, O. (2012). Impact of Rater Characteristics and Prosodic Features of Speaker Accentedness on Ratings of International Teaching Assistants' Oral Performance. Lang. Assess. Q. 9 (3), 249-269. doi:10.1080/ 15434303.2011.642631

Kang, O., and Moran, M. (2014). Functional Loads of pronunciation features in nonnative speakers' oral assessment. TESOL Q. 48 (1), 176-187.

Kang, O. (2010). Relative salience of suprasegmental features on judgments of L2 comprehensibility and accentedness. System 38 (2), 301-315.

Kang, O., Rubin, D., and Pickering, L. (2010). Suprasegmental Measures of Accentedness and Judgments of Language Learner Proficiency in Oral English. Mod. Lang. J. 94 (4), 554-566. doi:10.1111/j.15404781.2010.01091.x
Kang, O., Thomson, R. I., and Moran, M. (2020). Which features of accent affect understanding? Exploring the intelligibility threshold of diverse accent varieties. Appl. Linguistics 41 (4), 453-480.

Lee, J., Jang, J., and Plonsky, L. (2015). The effectiveness of second Language pronunciation instruction: A meta-analysis. Appl. Linguistics 36 (3), 345-366. doi:10.1093/applin/amu040

Pickering, L. (2001). The role of tone choice in improving ITA communication in the classroom. TESOL Q. 35 (2), 233-255.

Sewell, A. (2021). Functional Load and the teaching-Learning relationship in L2 pronunciation. Front. Commun. 6, 1-6. doi:10.3389/fcomm.2021.627378

Surendran, D., and Niyogi, P. (2003). Measuring the functional load of phonological contrastsTech. Rep. No. TR-2003-12). Chicago: Department of Computer Science, University of Chicago.

Conflict of Interest: The author declares that the research was conducted in the absence of any commercial or financial relationships that could be construed as a potential conflict of interest.

Publisher's Note: All claims expressed in this article are solely those of the authors and do not necessarily represent those of their affiliated organizations, or those of the publisher, the editors and the reviewers. Any product that may be evaluated in this article, or claim that may be made by its manufacturer, is not guaranteed or endorsed by the publisher.

Copyright (c) 2021 Sonsaat Hegelheimer. This is an open-access article distributed under the terms of the Creative Commons Attribution License (CC BY). The use, distribution or reproduction in other forums is permitted, provided the original author(s) and the copyright owner(s) are credited and that the original publication in this journal is cited, in accordance with accepted academic practice. No use, distribution or reproduction is permitted which does not comply with these terms. 